\title{
SPECTROSCOPIC OBSERVATIONS OF COMET KOHOUTEK (1973f)
}

\author{
Lubos Kohoutek and Jurgen Rahe
}

1. Introduction

Between January 5 and January 15, 1974, nine coudé spectrograns of Comet Kohoutek (1973f) were obtained with the ESO 352 -cr. telescope in La Silla, Chile. The emlision is Kodak I ia-O ( 3 plates) and Kodak $103 a-F$ (6 plates), the dispersion is $20.2 \AA / \mathrm{mm}$. The useful. spectral range extends from about $3500 \AA$ to about $5000 \AA$ (Kodak IIa-0 plates) and from about $4500 \&$ to about $6700 \&$ (Kodak 103a-F plates). The original scale was 4.55 arc sec/mm on the slit, and the full length of the siit was about 3 arc minutes. 1 mm on the piries corresponds to 66.5 arc sec, or about $3.9-44 \times 10^{4} \mathrm{~km}$ at the comet projected on the plane of the sky. The slit vas al.ways centered on the image of the cumet, and except for plate lio. 1436 , was orjented along the radius vector. A field rotator was used which dimished the stej.lar light by about $30:$

During the time of observation the heliocentric distance, $r$ and the geocentric distance, $\Delta$ of the comet varied from

$$
\begin{aligned}
& r=0.34-0.63 \mathrm{AU} \\
& \Delta=0.92-0.81 \mathrm{AU} .
\end{aligned}
$$

The pertinent observational. and conctary data are given in Table 1. All observations were severely influenced by large extinction. 


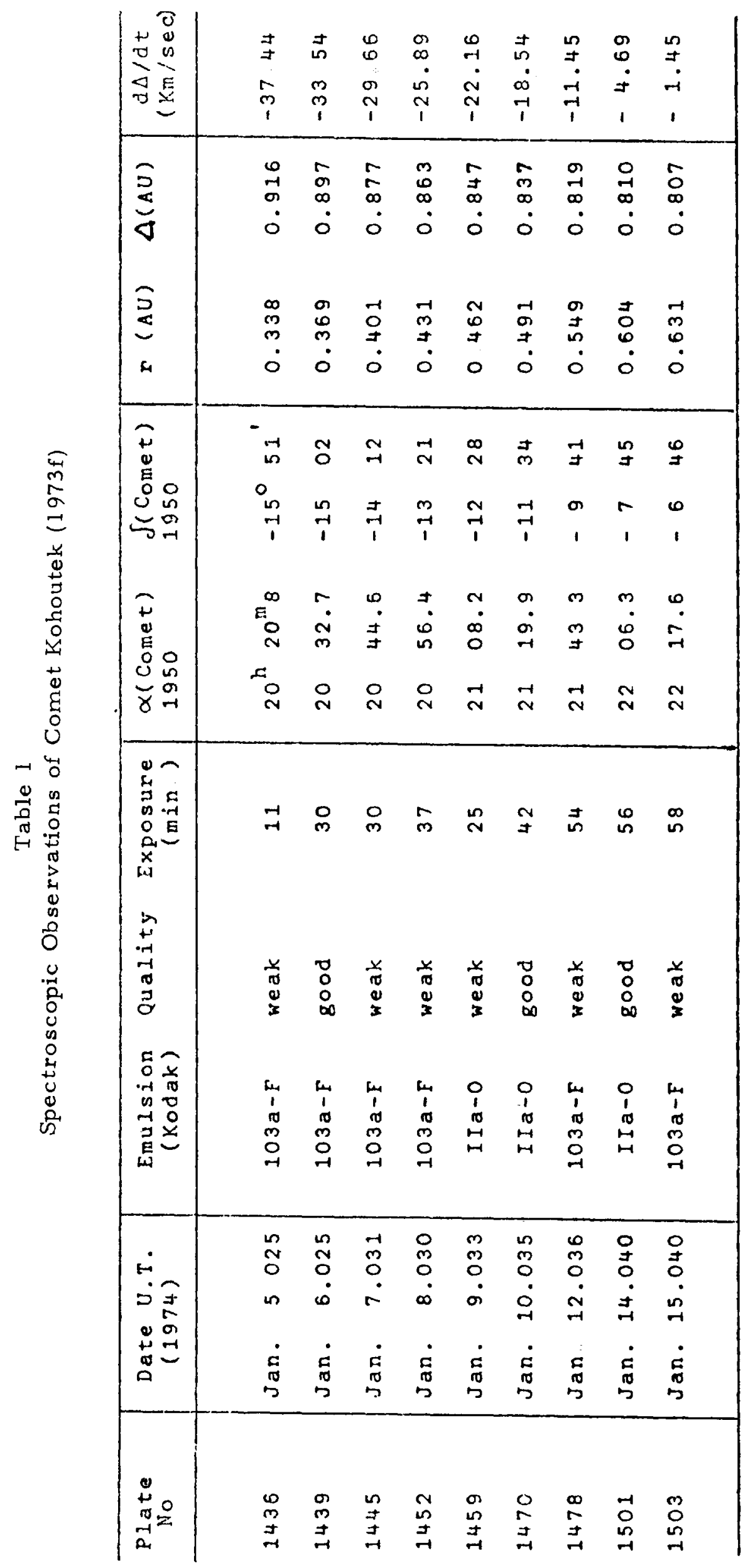




\section{Blue Region of the Spectrum}

In the Kodak IIa-O plates, the violet system of $C N$ and the $c_{2}$ Swan bands are dominating. In addition we find emission features of the $\mathrm{C}_{3}, \mathrm{CH}$, and $\mathrm{CO}^{+}$molecules. The (0-0) and the $(0-1)$ bands of the $\left(B^{2} \Sigma-X^{2} \Sigma\right)$ system of $C N$ are well resolved. On plate No. 1501 , the $(0-0)$ band could be traced up to $R(26)$. The much fainter $(1-1)$ band could not be detected. Tables 2 and 3 contain the wavelengths measured and corrected for the Doppler shift due to the geocentric radial velocity of the comet, the visual estimates of the corresponding intensities on an arbitrary scale, and the identifications. The identifications in these and the following tables are based on Johnson (1927), Shea (1927), Phillips (1948), Hunaerts (1950), Weinard (1955), Dressler and Ramsay (1959), Dossin et al. (1961), and Greenstein and Arpigny (1962).

The $\Delta v=+1$ sequence of the $c_{2}$ swan bands $\left(A^{3} \Pi-x^{3} \Pi\right)$ can easily be recognized. Of $c_{3}$ only three emissions could be found: $\lambda 4039.56 \&(I=1), \lambda 4043.42 \AA$ (2), $\lambda 4051.71 \AA$ (4). The (0-0) bands of the $\left(B^{2} \Sigma-x^{2} \Pi\right)$ and the $\left(A^{2} \Delta-x^{2} \Pi\right)$ systems of $\mathrm{CH}$ are present, the latter, however, always much stronger than the first which shows essentially the $P_{1}(1) \lambda 3892.93$ emission. Table 4 lists the identified $C H$ emissions of the $(0-0)$ band of the $\left(A^{2} \Delta-x^{2} \pi\right)$ system. $\mathrm{CO}^{+}$is present only in the best IIa-O plate (No. 1501) with 
Table 2

The $(0-0)$ Band of the $B^{2} \Sigma-X^{2} \Sigma$ System of $C N$

\begin{tabular}{|c|c|c|c|}
\hline $\begin{array}{l}\text { Inten- } \\
\text { sity }\end{array}$ & $\begin{array}{c}\lambda(\AA) \\
\text { (observed) }\end{array}$ & $\underset{\lambda(1}{\text { Ident }}$ & $\begin{array}{l}\text { ification } \\
\text { (Lab) }\end{array}$ \\
\hline 1 & 3852.32 & $R(26)$ & 3852.41 \\
\hline 0 & 3853.35 & $R(25)$ & 3853.50 \\
\hline 2 & 3855.66 & $R(23)$ & 3855.63 \\
\hline 1 & 3856.44 & $R(22)$ & 3856.67 \\
\hline 3 & $3857 \quad 65$ & $R(21)$ & 3857.68 \\
\hline 3 & 3858.67 & $R(20)$ & 3858.64 \\
\hline 4 & 3859.67 & $R(19)$ & 3859.67 \\
\hline 1 & 3860.58 & $R(18)$ & 3860.60 \\
\hline 2 & 3861.52 & $R(17)$ & 386154 \\
\hline 6 & 3862.40 & $R(16)$ & 3862.48 \\
\hline 9 & 3863.31 & $R(15)$ & 3863.40 \\
\hline 6 & 3864.23 & $R(14)$ & 3864.30 \\
\hline 9 & 3865.08 & $R(13)$ & $3865 \quad 16$ \\
\hline 6 & 3865.91 & $R(12)$ & 3865.99 \\
\hline 10 & 3866.75 & $R(11)$ & 3866.82 \\
\hline 8 & $3867 \quad 61$ & $R(10)$ & $3867 \quad 62$ \\
\hline 8 & 3868.36 & $R(9)$ & 3868.41 \\
\hline 11 & 3869.05 & $R(8)$ & 3869.18 \\
\hline 9 & 3869.82 & $R(7)$ & 386992 \\
\hline 1 & 3870.58 & $R(6)$ & 3870.65 \\
\hline 3 & 3871.25 & $R(5)$ & 3871.37 \\
\hline 6 & 3872.03 & $R(4)$ & 3872.05 \\
\hline 3 & 3872.62 & $R(3)$ & 3872.74 \\
\hline 5 & 3873.29 & $R(2)$ & 3873.37 \\
\hline 5 & 3873.98 & $R(1)$ & 3874.00 \\
\hline 0 & 3874.61 & $R(0)$ & 3874.61 \\
\hline on & 3875.84 & $P(2)$ & 3876.32 \\
\hline 3 & 3876.70 & $P(3)$ & 3876.84 \\
\hline 2 & 3877.20 & $P(4)$ & 3877.35 \\
\hline 1 & 3877.41 & $P(5)$ & 3877.84 \\
\hline $6 n$ & 3881.05 & $P(13)$ & 3880.99 \\
\hline \multirow[t]{2}{*}{$6 n$} & 3882.05 & $\int P(14)$ & $3881 \quad 30$ \\
\hline & & $f P(15)$ & $3881 \quad 58$ \\
\hline $6 \mathrm{n}$ & 3882.99 & Head & 3883.39 \\
\hline
\end{tabular}


Table 3

The $(0-1)$ Band of the $\mathrm{B}^{2} \Sigma-\mathrm{X}^{2} \Sigma$ System of $\mathrm{CN}$

\begin{tabular}{c|c|c}
\hline $\begin{array}{c}\text { Inten- } \\
\text { sity }\end{array}$ & $\begin{array}{c}\lambda(\AA) \\
(\text { observed) }\end{array}$ & $\begin{array}{c}\text { Identification } \\
\lambda\end{array}$ \\
\hline 1 & 4195.97 & $\mathrm{R}(13) 4195.94$ \\
1 & 4198.02 & $\mathrm{R}(11) 4198.09$ \\
0 & 4206.02 & $\mathrm{R}(2) 4206.19$ \\
1 & 4207.04 & $\mathrm{R}(1) 4206.95$ \\
1 & 4211.85 & $\mathrm{P}(6) 4211.90$ \\
3 & 4215.60 & $\mathrm{P}(17) 4215.55$ \\
& Head & $\mathrm{P}(18) 4215.68$ \\
\hline
\end{tabular}


Table 4

The $(0-0)$ Band of the $A^{2} \Delta-X^{2}$ II system of $C H$

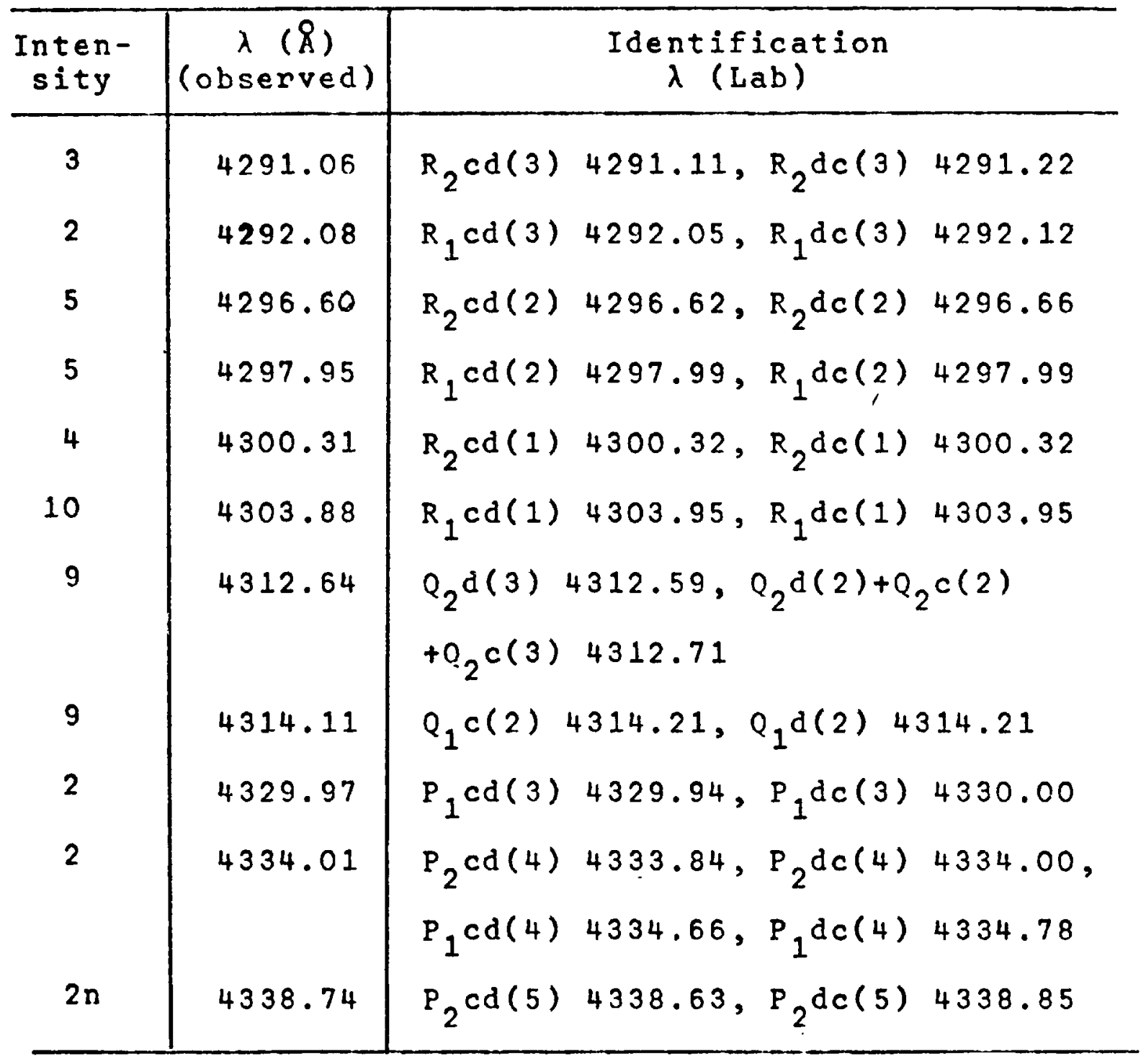

Table 5

$\mathrm{CO}^{+}$Bands

\begin{tabular}{c|c|c|}
\hline$\left(v^{\prime}-v^{\prime \prime}\right)$ & $\lambda(\AA)$ & \multicolumn{2}{|c}{ System } \\
\hline$(1-0)$ & $4568-4544$ & $A^{2} \Pi-x^{2} \Sigma \quad$ Comet Tail \\
$(2-0)$ & 4252 & $A^{2} \Pi-x^{2} \Sigma \quad$ Comet Tail \\
$(2-1)$ & $4711-4683$ & $A^{2} \Pi-x^{2} \Sigma \quad$ Comet Tail \\
$(0-1)$ & 4231 & $B^{2} \Sigma-x^{2} \Pi \quad$ Baldet-Johnson \\
\hline
\end{tabular}


Table 6

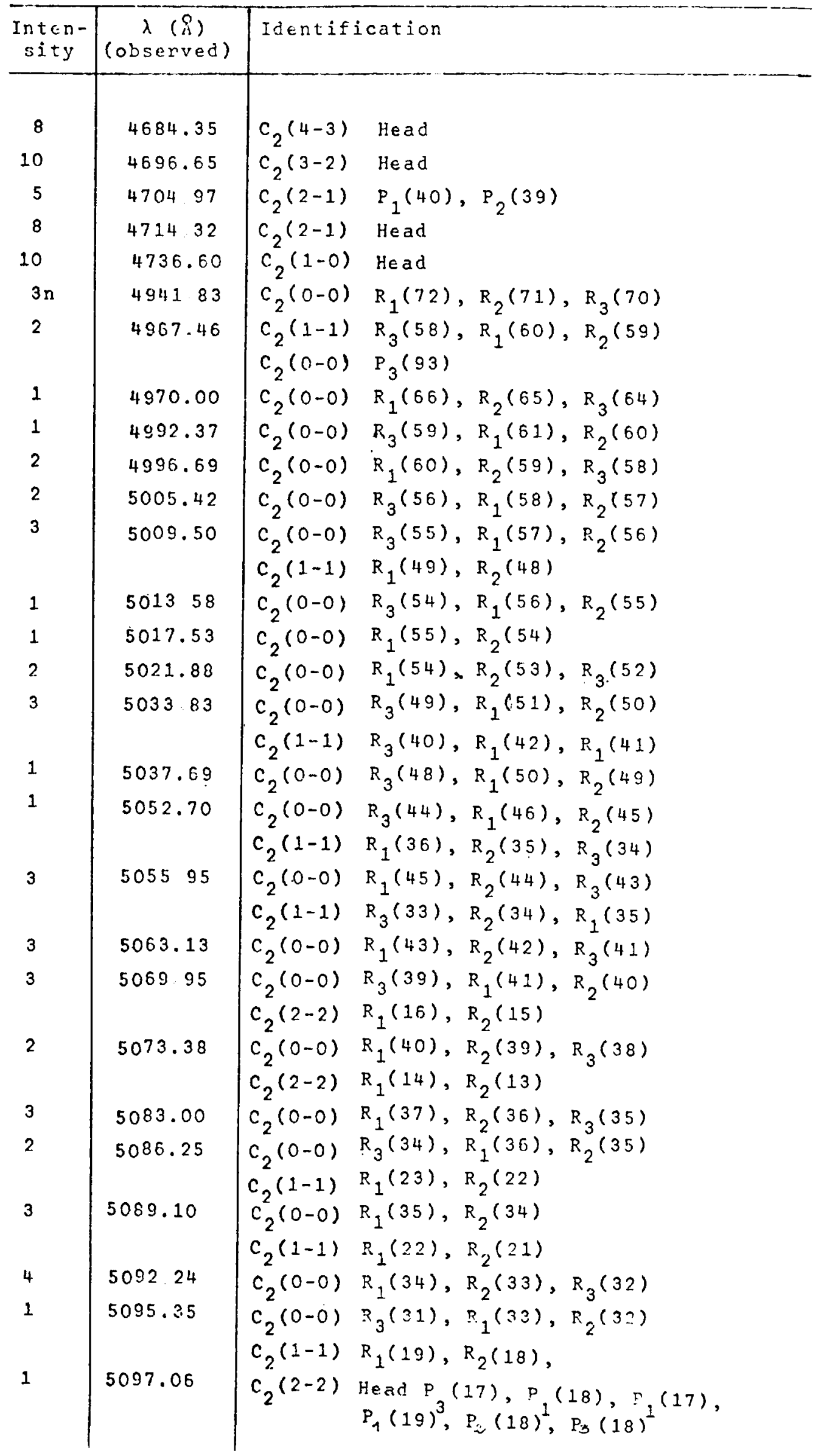


Table 6 ('ontinued)

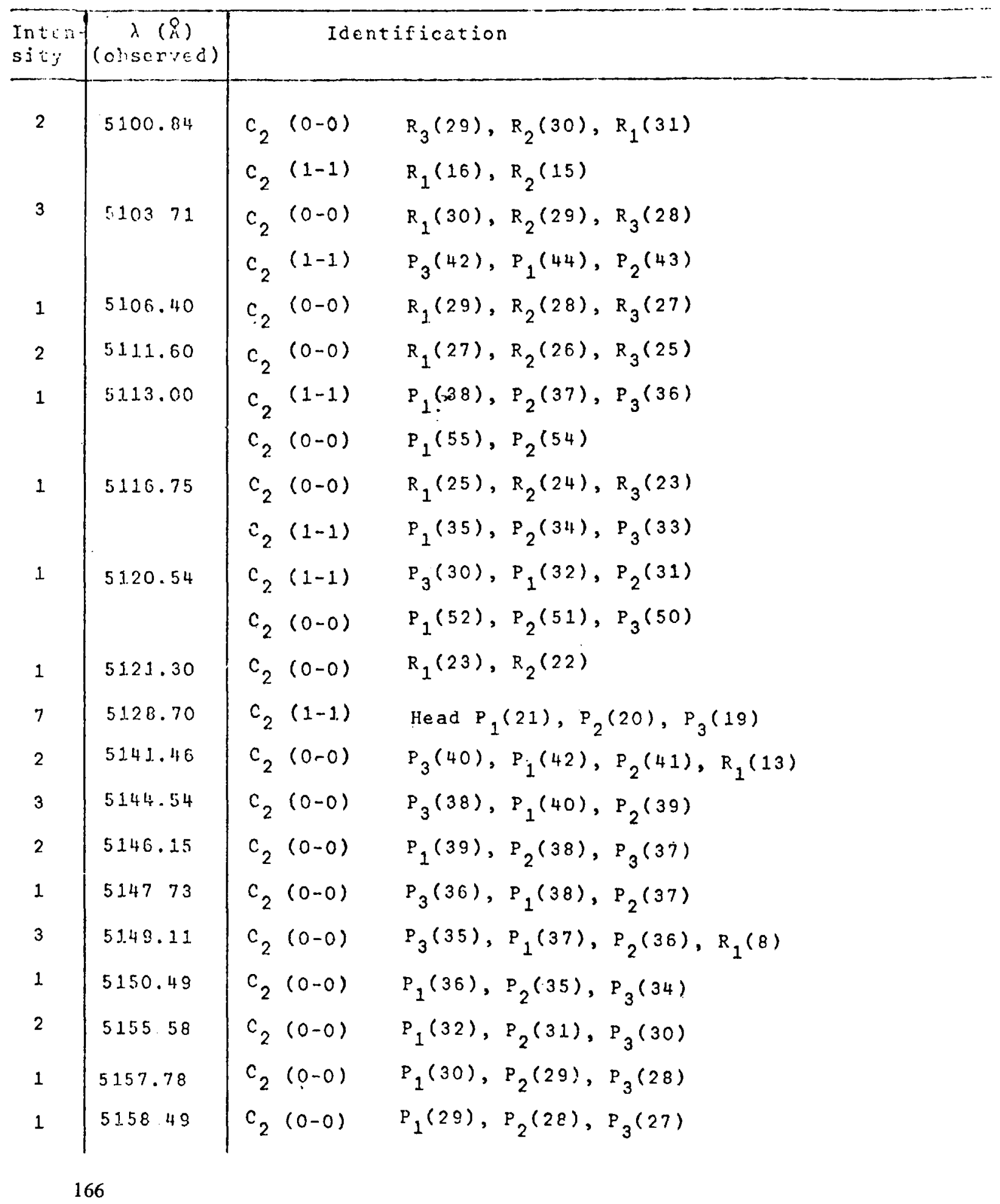


Table 6 (Continued)

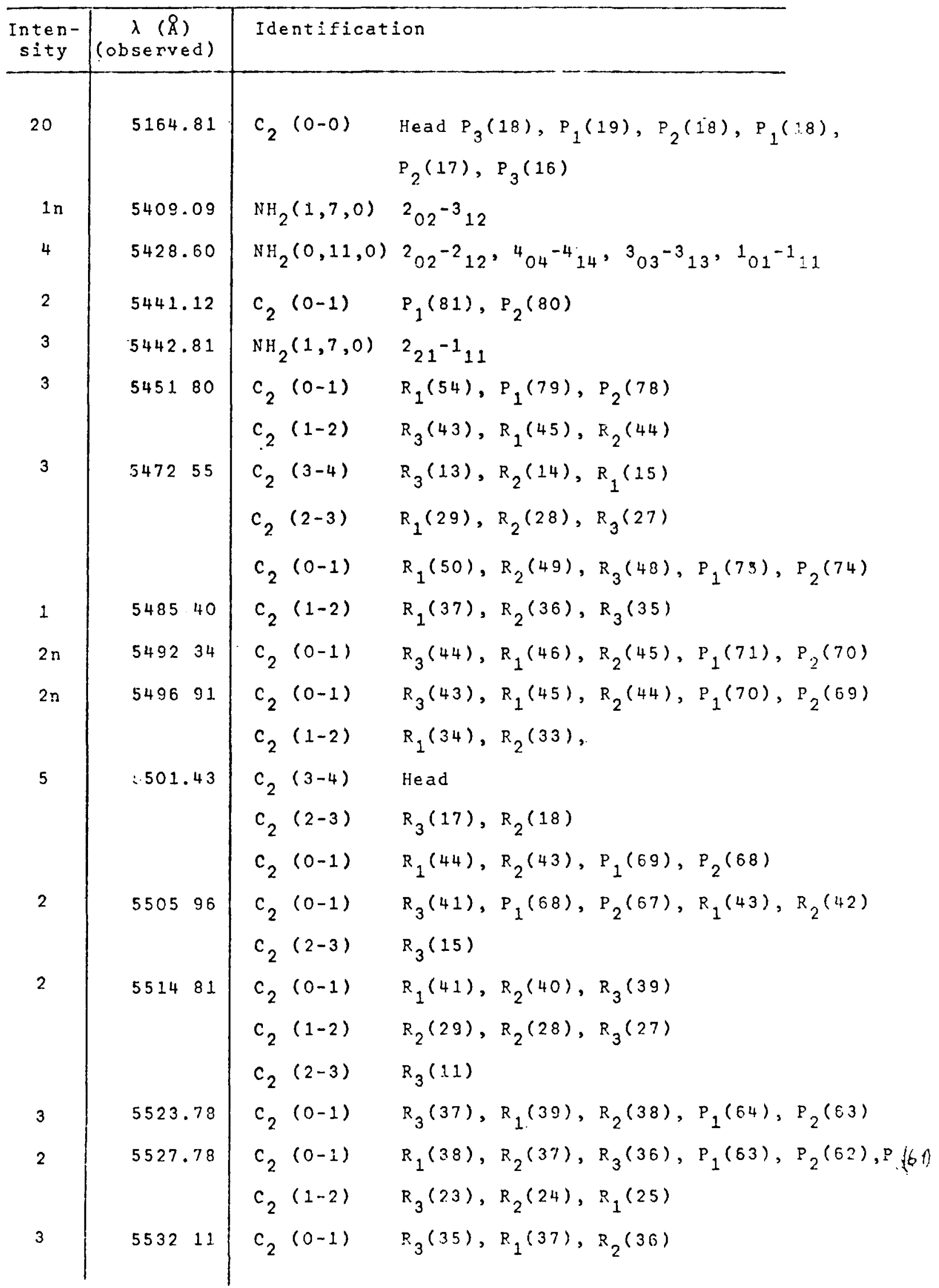


Table $6 \quad$ (Continued)

\begin{tabular}{|c|c|c|c|}
\hline $\begin{array}{l}\text { Inten- } \\
\text { sity }\end{array}$ & $\begin{array}{c}\lambda(\AA) \\
\text { (observed) }\end{array}$ & Identificatio & \\
\hline 3 & 5536.26 & $c_{2}(0-1)$ & $R_{3}(34), P_{1}(61), P_{2}(60), R_{1}(36), R_{2}(35)$ \\
\hline 1 & 5537.52 & $c_{2}(2-3)$ & $P_{3}(20), P_{1}(22), P_{2}(21)$ \\
\hline 4 & 5540.20 & $c_{2}(2-3)$ & $\begin{array}{l}\text { Head } P_{3}(17), P_{1}(18), P_{2}(17), P_{2}(16), P_{3}(16 \\
P_{3}(15), P_{2}(15), P_{2}(14), P_{3}(14), P_{2}(13)\end{array}$ \\
\hline 2 & $5544: 04$ & $c_{2}(0-1)$ & $\begin{array}{l}R_{1}(34), R_{2}(33), R_{3}(32), P_{1}(59) \\
P_{2}(58)\end{array}$ \\
\hline 2 & 5551.54 & $c_{2}(0-1)$ & $R_{2}(32), R_{2}(31), R_{3}(30), P_{1}(57), P_{2}(56)$ \\
\hline 2 & $5559 \cdot 10$ & $c_{2}(0-1)$ & $R_{3}(28), P_{1}(55), P_{2}(54), P_{3}(53)$ \\
\hline 3 & $5565 \cdot 68$ & $\begin{array}{l}c_{2}(0-1) \\
c_{2}(1-2)\end{array}$ & $\begin{array}{l}R_{1}(28), R_{2}(27), R_{3}(26), P_{1}(53), P_{2}(52) \\
P_{3}(33), P_{1}(35)\end{array}$ \\
\hline 1 & $5569 \cdot 20$ & $\begin{array}{l}c_{2}(0-1) \\
c_{2}(1-2)\end{array}$ & $\begin{array}{l}R_{2}(26), R_{3}(25), R_{1}(27) \\
P_{3}(31)\end{array}$ \\
\hline 2 & 5572.38 & $\begin{array}{l}c_{2}(0-1) \\
c_{2}(1-2)\end{array}$ & $\begin{array}{l}R_{1}(26), P_{2}(25) \\
P_{3}(29), P_{1}(31), P_{2}(30)\end{array}$ \\
\hline 10 & 5585.02 & $c_{2}(0-1)$ & $\begin{array}{l}\text { Head } P_{1}(18), P_{2}(17), P_{3}(16), P_{1}(17), \\
P_{2}(16), P_{3}(15), P_{1}(16), P_{2}(15), P_{1}(15), \\
P_{2}(14), P_{3}(14), P_{1}(14), P_{2}(13) \\
R_{1}(22), R_{2}(21), R_{3}(20), P_{1}(47), F_{2}(46)\end{array}$ \\
\hline In & 5588.07 & $c_{2}(0-1)$ & $P_{1}(46), P_{2}(45), P_{3}(44)$ \\
\hline 1 & $5590 \quad 70$ & $c_{2}(0-1)$ & $R_{3}(18), P_{1}(45), P_{2}(44), R_{2}(19)$ \\
\hline 1 & $5593 \quad 55$ & $\begin{array}{l}\mathrm{C}_{2}(0-1) \\
\mathrm{NH}_{2}(0,11,0)\end{array}$ & $\begin{array}{l}R_{3}(17), P_{1}(44), P_{2}(43), P_{3}(42) \\
5_{41^{-4} 31}\end{array}$ \\
\hline 1 & 5595.99 & $c_{2}(0-1)$ & $R_{1}(18), R_{2}(17), R_{3}(16), P_{1}(43), P_{2}(42)$ \\
\hline 2 & 5600.72 & $c_{2}(0-1)$ & $R_{1}(16), R_{2}(15), R_{3}(14), P_{1}(41), P_{2}(40)$ \\
\hline In & 5612.33 & $c_{2}(0-1)$ & $P_{1}(36), P_{2}(35), P_{3}(34)$ \\
\hline $\ln$ & $5614 \quad 27$ & $c_{2}(0-1)$ & $P_{1}(35), P_{2}(34), P_{3}(33)$ \\
\hline
\end{tabular}


Table 6 (Continued)

\begin{tabular}{|c|c|c|c|}
\hline $\begin{array}{c}\text { Inten- } \\
\text { sity }\end{array}$ & $\mid \begin{array}{c}\lambda(\AA) \\
(\text { observed) }\end{array}$ & Identificat & ion \\
\hline 6 & 5635.06 & $c_{2}(0-1)$ & $\begin{array}{l}\text { Head } P_{3}(14), P_{3}(15), P_{1}(17), P_{2}(16) \\
P_{3}(16)\end{array}$ \\
\hline 2 & $\begin{array}{lll}5703 & 06\end{array}$ & $\mathrm{NH}_{2}(0,10,0)$ & $212^{-2} 02$ \\
\hline 30 & 5889.92 & $\mathrm{Na} I$ & $D_{2}$ \\
\hline 20 & 5895.89 & $\mathrm{Na} \mathrm{I}$ & $D_{1}$ \\
\hline 1 & 5939.47 & $\mathrm{NH}_{2}(0,10,0)$ & $5_{32}^{-6} 42$ \\
\hline 6 & $\begin{array}{lll}5977 & 02\end{array}$ & $\begin{array}{l}\mathrm{C}_{2}(3-5) \\
\mathrm{NH}_{2}(0,9,0)\end{array}$ & $\begin{array}{l}R_{2}(11), R_{1}(12) \\
{ }_{03}^{-3} 13,{ }_{05}{ }^{-5} 15,1_{01}{ }^{-1} 11^{2}, 2^{-2} 12\end{array}$ \\
\hline 5 & 5994.96 & $\begin{array}{l}\mathrm{NH}_{2}(0,9,0) \\
\mathrm{C}_{2}(1-3) \\
\mathrm{C}_{2}(3-5)\end{array}$ & $\begin{array}{l}1_{01}-211 \\
R_{1}(37), R_{2}(36), R_{3}(35) \\
P_{1}(26), P_{2}(25)\end{array}$ \\
\hline 3 & $6004 \quad 21$ & $\begin{array}{l}\mathrm{C}_{2}(3-5) \\
\mathrm{NH}_{2}(0,9,0)\end{array}$ & $\begin{array}{l}\text { Head } \\
4_{23} 3^{-3} 13\end{array}$ \\
\hline 5 & 6020.03 & $\begin{array}{l}\mathrm{NH}_{2}(0,3,0) \\
\mathrm{C}_{2}(1-3)\end{array}$ & $\begin{array}{l}{ }^{3} 03^{-4} 13 \\
R_{2}(31), R_{3}(30)\end{array}$ \\
\hline 3 & 6033.56 & $\begin{array}{l}\mathrm{C}_{2}(1-3) \\
\mathrm{C}_{2}(2-4) \\
\mathrm{NH}_{2}(0,9,0)\end{array}$ & $\begin{array}{l}R_{1}(29), R_{2}(28), R_{3}(27) \\
P_{1}(34), P_{2}(33) \\
3_{21}-313\end{array}$ \\
\hline $3 n$ & 6059.14 & $c_{2}(2-4)$ & Head \\
\hline 1 & 6081.51 & $\mathrm{NH}_{2}(0,9,0)$ & $423^{-4} 31$ \\
\hline 1 & 6096.71 & $\mathrm{NH}_{2}(0,9,0)$ & $2_{21}-331,2_{20}^{-3} 30$ \\
\hline 2 & $6098 \quad 44$ & $\mathrm{NH}_{2}(0,9,0)$ & ${ }^{2} 20^{-3} 30^{,}{ }^{2} 21^{-3} 31$ \\
\hline 3 & 6121.86 & $c_{2}(1-3)$ & Head \\
\hline 2 & $6190 \quad 74$ & $c_{2}(0-2)$ & Head \\
\hline
\end{tabular}


Table 6 (Continued)

\begin{tabular}{|c|c|c|}
\hline $\begin{array}{c}\text { Inten- } \\
\text { sity }\end{array}$ & $\begin{array}{c}\lambda(\AA) \\
\text { (observed) }\end{array}$ & Identification \\
\hline 1 & 625589 & $\mathrm{NH}_{2}(0,9,0) \quad 6_{43}-633$ \\
\hline 1 & $6274 \quad 28$ & $\mathrm{NH}_{2}(0,8,0) \quad{ }^{3}{ }_{12}^{-2} \mathrm{O} 2$ \\
\hline 1 & 6297.32 & $\mathrm{NH}_{2}(0,8,0) \quad 2_{12}-2 \mathrm{O} 2$ \\
\hline 2 & $6298 \quad 58$ & $\mathrm{NH}_{2}(0,8,0) \quad 2_{12}-202$ \\
\hline 10 & 6300.33 & $\begin{array}{l}\mathrm{NH}_{2}(0,8,0){ }^{4} 14^{-4} 04,{ }^{6} 16^{-6} 06 \\
{[\mathrm{OI}]}\end{array}$ \\
\hline 3 & 633456 & $\mathrm{NH}_{2}(\mathrm{Em})$ \\
\hline 1 & $6357 \quad 46$ & $\mathrm{NH}_{2}(0,8,0) \quad{ }^{3} \cdot 13^{-4} 23$ \\
\hline 2 & 636031 & $\mathrm{NH}_{2}(0,8,0) \quad 3_{12}-422$ \\
\hline 2 & 6363.87 & {$[0 I]$} \\
\hline 1 & 6601.40 & $\mathrm{NH}_{2}(0,7,0) 3_{03}-211,{ }^{4} 04^{-3} 12,5_{05}^{-4} 13$ \\
\hline 1 & $6618 \quad 07$ & $\mathrm{NH}_{2}(0,7,0) 1_{01}^{-1} 11$ \\
\hline 2 & 6619.08 & $\mathrm{NH}_{2}(0,7,0) 5_{05}-515,3_{03}-313,2_{02}-212$ \\
\hline 2 & $6640: 62$ & $\mathrm{NH}_{2}(0,7,0) 1_{01}-211$ \\
\hline 2 & 6671.47 & $\mathrm{NH}_{2}(0,7,0) 3_{03}^{-4} 13$ \\
\hline
\end{tabular}


its emissions given in Table 5. It was too faint to be seen in any other spectrum.

\section{Visual Region of the Spectrum}

Table 6 contains the list of the measured emissions in the visual region of the spectrum with wavelengths $\lambda \lambda 4684-6671 \&$ (Kodak 103a-F plates) together with the corresponding identifications. We find essentially the sequences $\Delta \mathrm{v}=0, \Delta \mathrm{v}=-1$, and $\Delta \mathrm{v}=-2$ of the $\mathrm{c}_{2}$ swan bands: and $\mathrm{NH}_{2}$ Emissions. Since $\mathrm{HH}_{2}$ is more concentratéd towards the nucleus than $C_{2}$, it is easier lost in the continuum than $\mathrm{C}_{2}$. In addition to $\mathrm{C}_{2}$ and $\mathrm{NH}_{2}$, the $\mathrm{NaI} \mathrm{D}_{1}$ and $\mathrm{D}_{2}$ lines are very strong, and forbidden [OI] can also be identified. New lines could not be detected.

4. Discussion

The sodium doublet ( $5889.97 \AA, 5895.93 \AA)$ was very strong at small heliocentric distances $(0.3-0.4 \mathrm{AU})$, but later it weakened considerably. The intensity distribution along the lines is given in Figures 1 and 2. The profiles are remarkably asymmetric with respect to the nucleus; the gradient on the sunward side ( $S$ ) is much steaper than on the tail side (RV). The intensity decrease of ra in the nucleocentric distance between 2 and $5 \times 10^{3} \mathrm{~km}$ on the sunvard side and between 2 and $7 \times 10^{3} \mathrm{~km}$ on the tail side is approximately linear with a mean slope of -20 and -12 , respectively Torards the sun, $\mathrm{Na}$ extends to about $1.2 \times 10^{4} \mathrm{~km}$, 


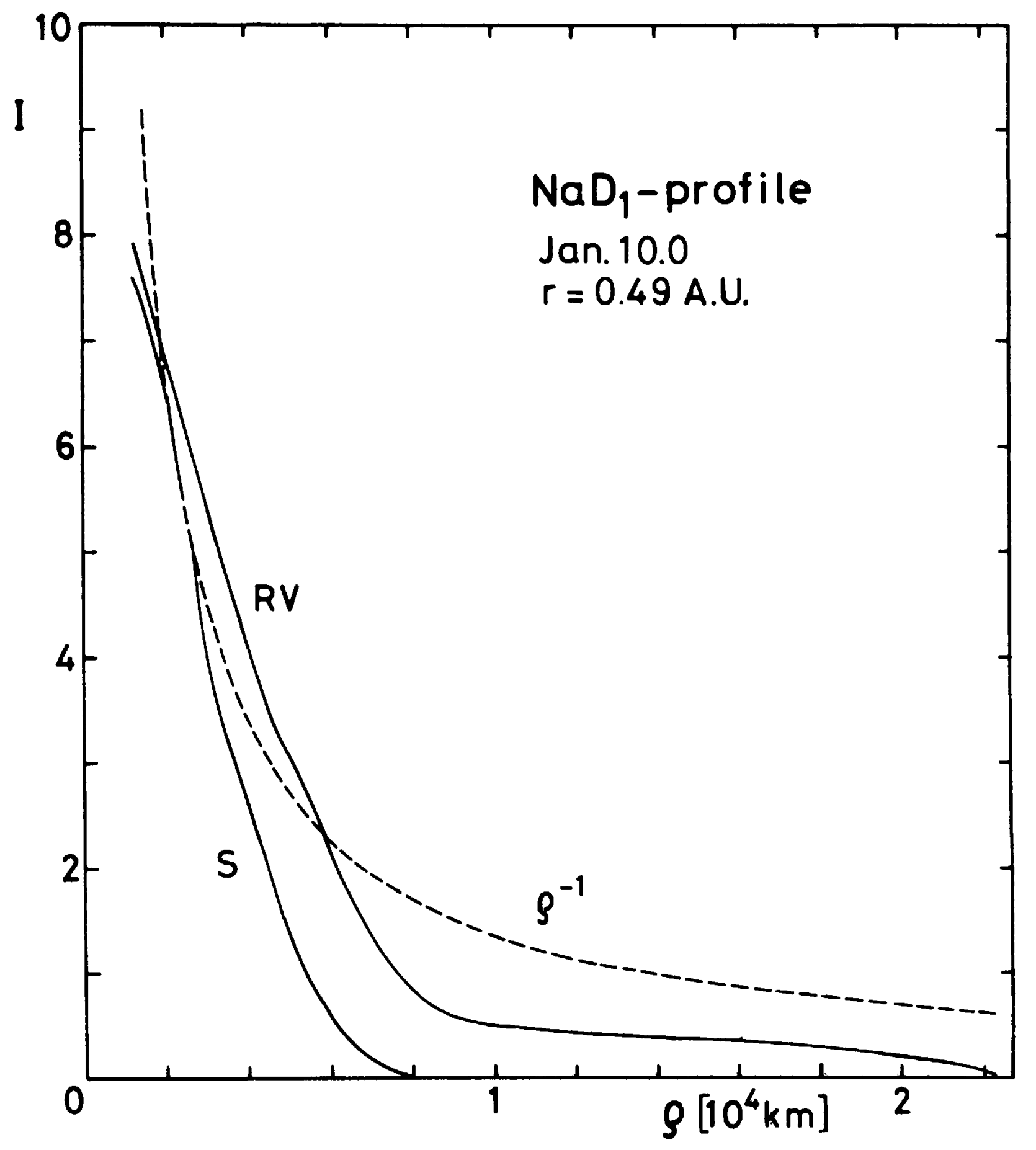

Figure 1: Na D 1 -profile on January $10.035 \mathrm{UT}$, 1974, at $r=$ $0.49 \mathrm{AU}$. The intensity (I) is given in arbitrary units as function of the distance $(\rho)$ from the nucleus in units of $10^{4} \mathrm{~km}$ in the direction towards the sun, (S); and in the tail direction, (RV). The dashed curve is calculated for an intensity lar $I(p) \sim \rho^{-1}$. 


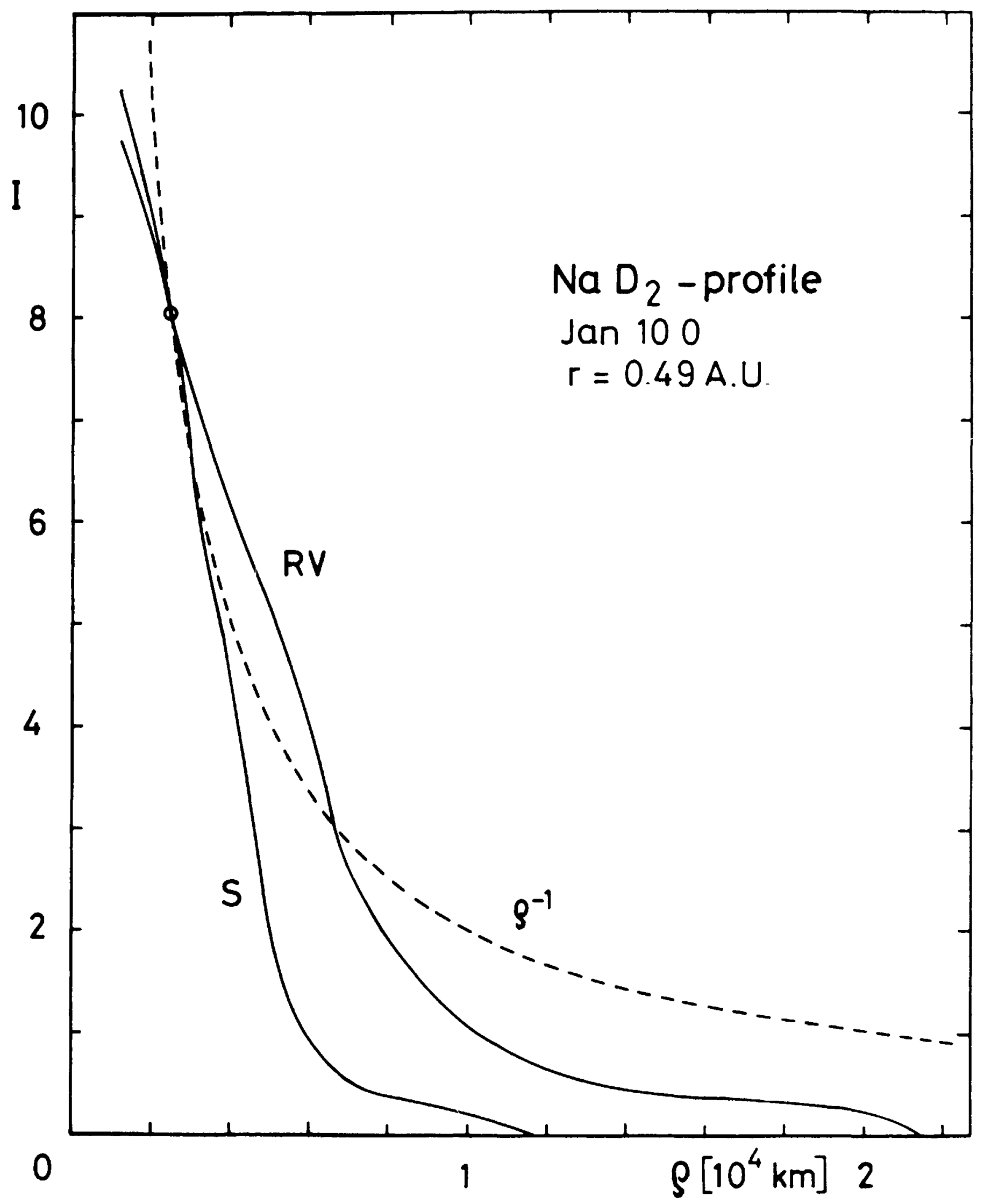

Figure 2: $\mathrm{Na} \mathrm{D}$-profile on January $10.035 \mathrm{UT}$, 1974, at $r=$ $0.49 \mathrm{AU}$. For details see Fig. 1. 
in the tail direction up to over $2 \times 10^{4} \mathrm{~km}$. This asymmetry is caused by radiation pressure. Due to their larger f-values, the Na D-lines are more sensitive to this effect than the neutral molecular emissions $\left(f(C N)=3 \times 10^{-2}, f\left(C_{2}=3 \times 10^{-3}\right)\right.$ which are nearly symmetric to the nucleus as is illustrated in Fig. 3, showing the $c_{2} \lambda 4737 \AA$-profile on January 14 , 1974. The $\rho^{-1}$-law fits relatively well for both $C_{2}$ curves, (S) and $(R V)$, indicating a density law $D(\rho) \sim \rho^{-2}$ for the radiating $C_{2}$ molecules. On the other hand, the density distribution of $\mathrm{Na}$ atoms can be approximated neither by the simple law $D(\rho) \sim \rho^{-2}$, nor by $D(\rho) \sim \rho^{-2} e^{-\left(\rho / \rho_{0}\right)}$ (Haser, 1957; Hurm and Balazs, 1963) and should be investigated in more detail. We observe a similar behavior as for Comets Mrkos $1957 \mathrm{~V}$ (Greenstein and Arpigny, 1962) and Bennett 1970 II (Rahe et al, 1975 ).

The intensity evolution of the main emission bands during the period of observation is given in Tables 7 and 8 . The intensity values refer to the intensity of the region close to the nucleus (up to about $10^{4} \mathrm{~km}$ ) and are given relative to the brightness of the violet $(0-1)$ band of $C N$ (Tabie 7) or to that of the $(1-2)$ Swan band of $C_{2}$ (Table 8) which are both normalized to 10.0 .

The $c_{2}(1-0)$ intensity increases relative to the $C N(0-1)$ emission with increasing heliocentric distance (Table 7 , $r=0.46-0.60 \mathrm{AU})$. The $\mathrm{CO}^{+}$emission, though very faint, decreases relative to $\mathrm{CN}$ as the comet recedes from the sun while the Cri emission clearly increases $A t r=0.46 \mathrm{AU}$ the $\mathrm{CH}$ lines are ctill rather weak, but strengthen with growing $r$ 


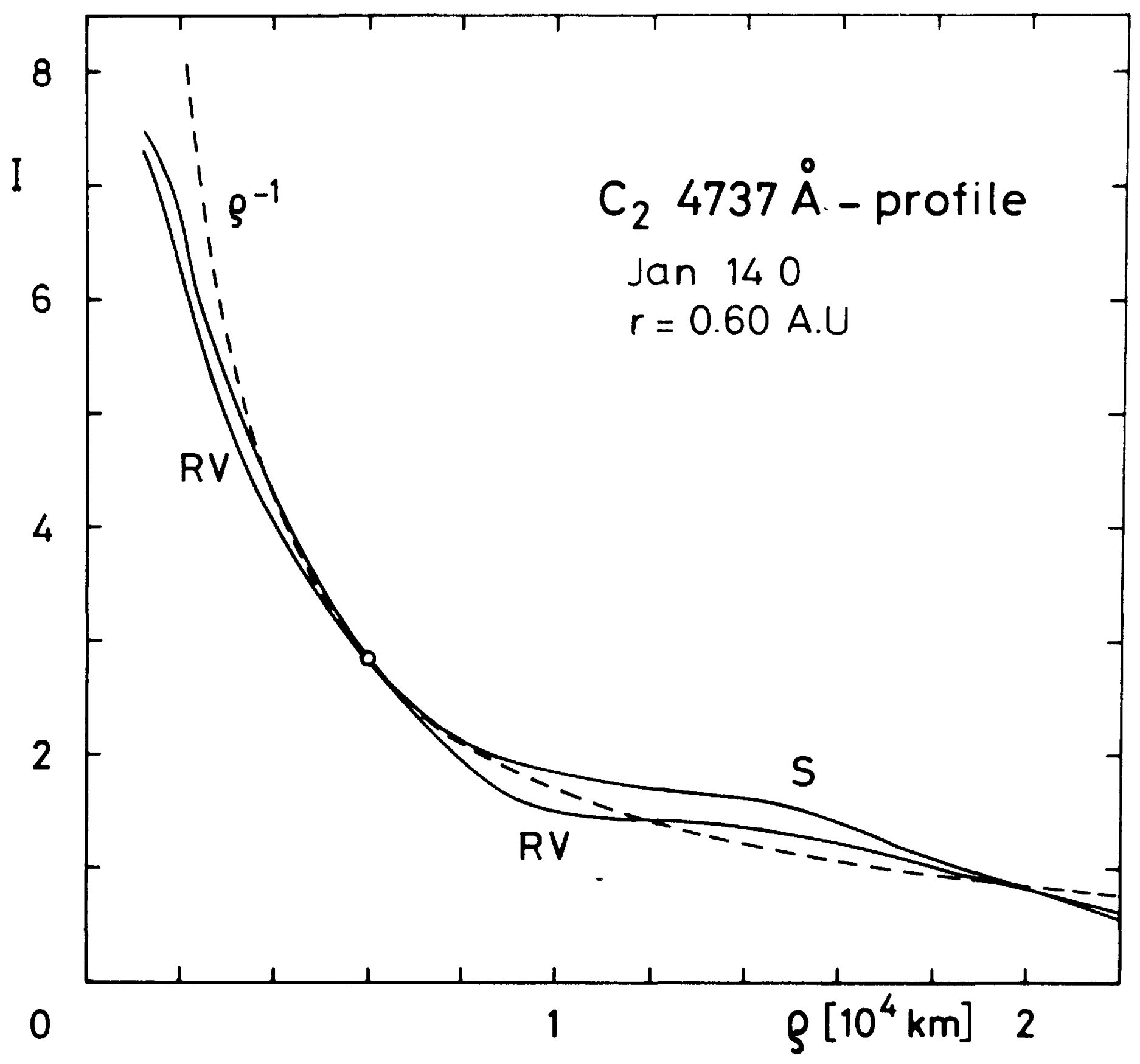

Figure $3: c_{2} \lambda 4737 \AA$-profile as observed on January 14.040 UT, 1974 , at $r=0.60$ AU. For details see Fig. 1. 


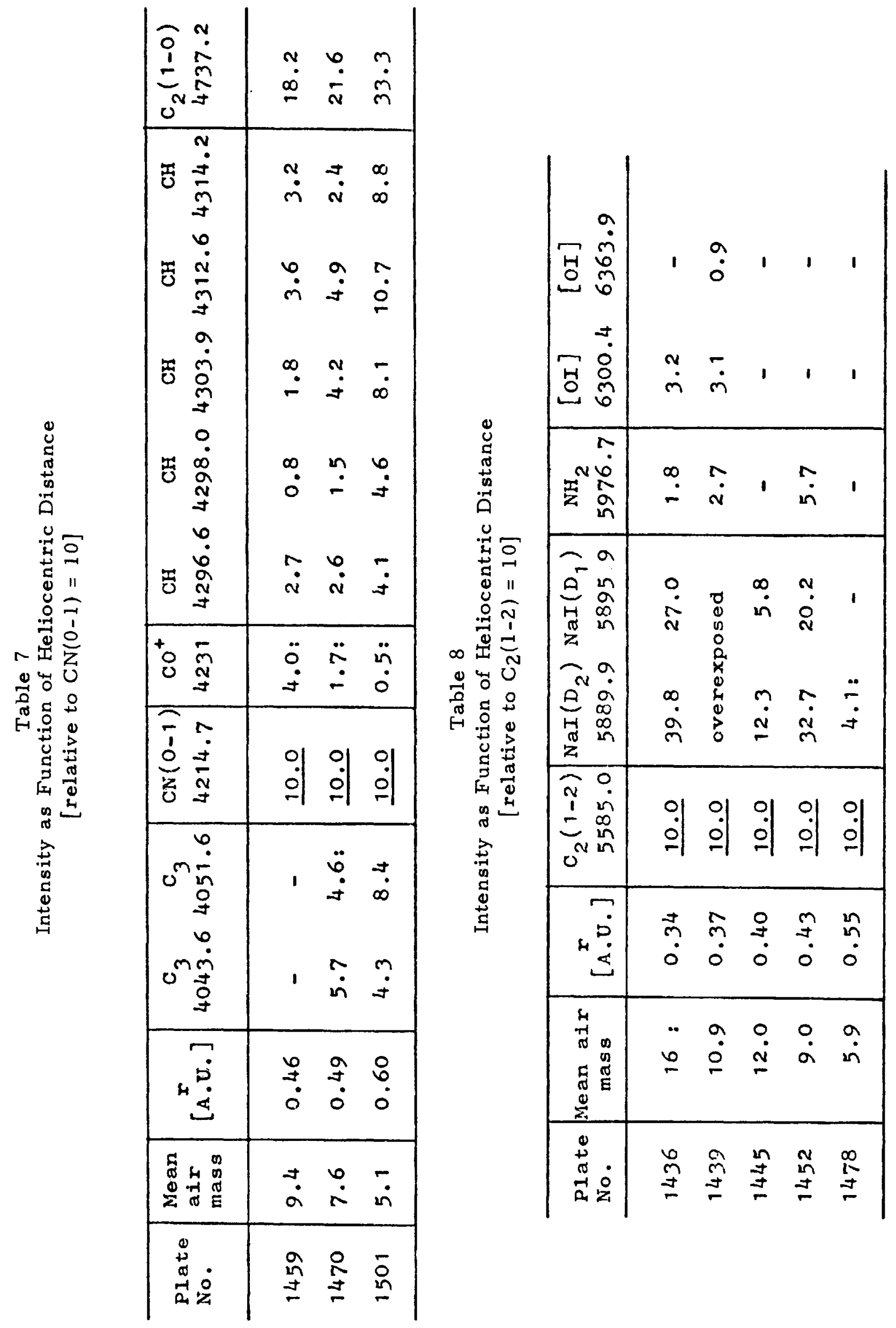


(see also Fig. 4). For the first two plates $(r=0.46$ and $0.49 \mathrm{AU})$, the lines $4291-4300 \&$ of the $R$-branch of the $\mathrm{CH}\left(\mathrm{A}^{2} \Delta-\mathrm{X}^{2} \Pi\right)$ system are weaker than the $(0-1)$ band of $\mathrm{CN}$, in the thind spectrum (plate No.1501, $r=0.60 \mathrm{AU}$ ) both intensities are comparable. The brightness of the 4312 and $4314 \AA$ emissions of the Q-branch even excels that of the $\mathrm{CN}(0-1)$ sequence. The strength of $\mathrm{NH}_{2}$ also grows as compared to $c_{2}(1-2)$ (Table $\left.8, r=0.34-0.55 \mathrm{AU}\right)$, whereas the intensity of the sodium doublet drops considerably at the same time by about one order of magnitude. It was very strong between January 5 and January 8 at $r=0.34$ and $r=$ $0.43 \mathrm{AU}$, respectively, but had nearly vanished on January 12 at $r=0.55 \mathrm{AU}$ (see also Kohoutek, 1975). However, a pronounced increase in the $\mathrm{Na}$ brigthness occured on January 8 at $r=0.43$ AU (piate No. 1452). The average intensity ratio of the two sodium $D$ lines was $I\left(D_{2}\right) / I\left(D_{1}\right)=1.7$ which is in agreement with the resonance fluorescence hypothesis, according to which this ratio should be $\leq 2$. It is certainly smaller than the intensity ratio $I\left(D_{2}\right) / I\left(D_{1}\right)=2.5$ determined by Warner (1963) from the spectrum of comet Seki-Lines 1962 III.

The $\mathrm{C}_{3}$ and the $[\mathrm{OI}$ ] observations are too limited to allow any conclusion.

The spatial extension of different emissions as function of heliocentric distance can be compared in Table 9. The dimensions are determined along the spectral lines (i.e., their lengths perpendicular to the dispersion) and are clearly limited by exposure time and plate emulsion, thus giving only lower limits of the actual extension of the 


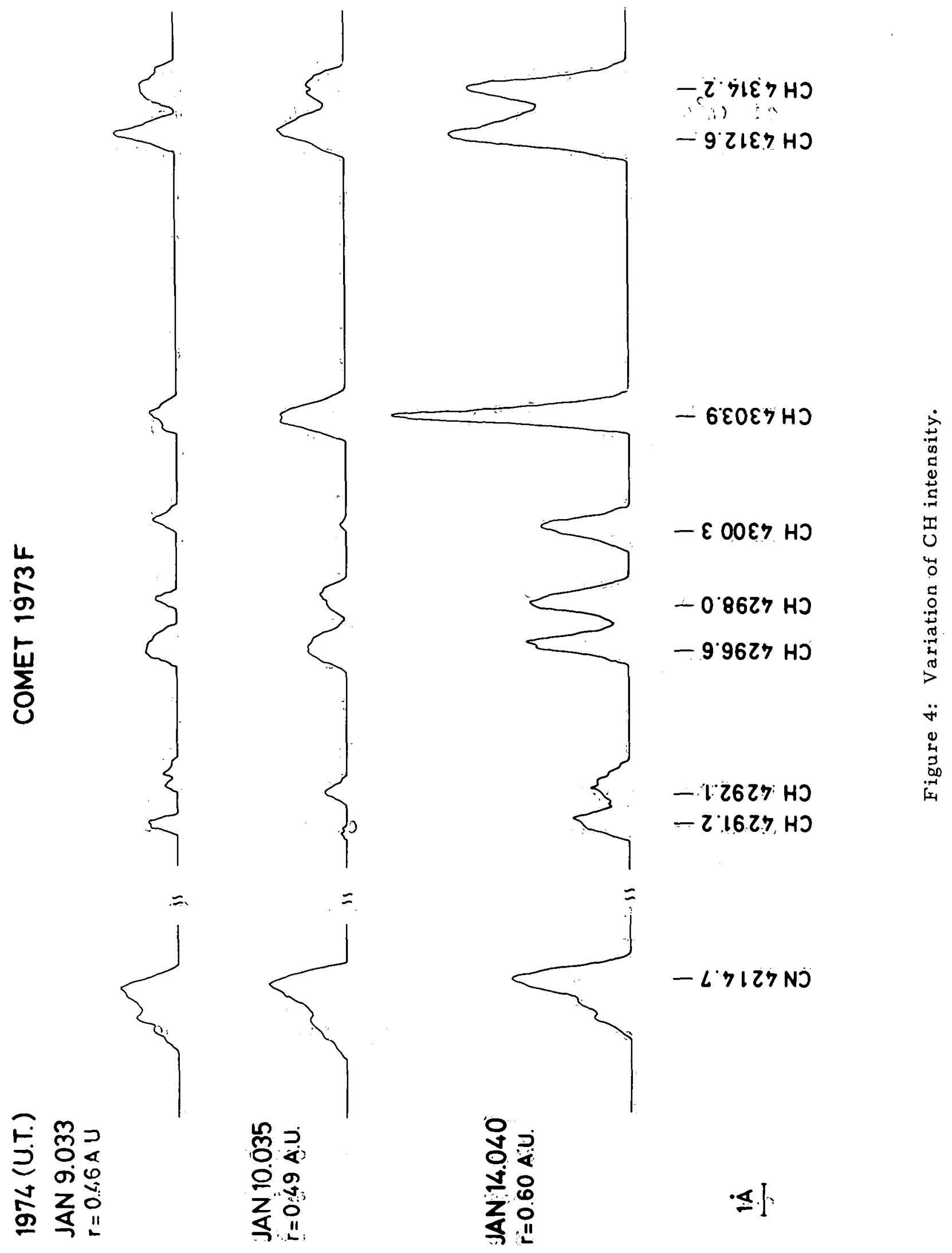




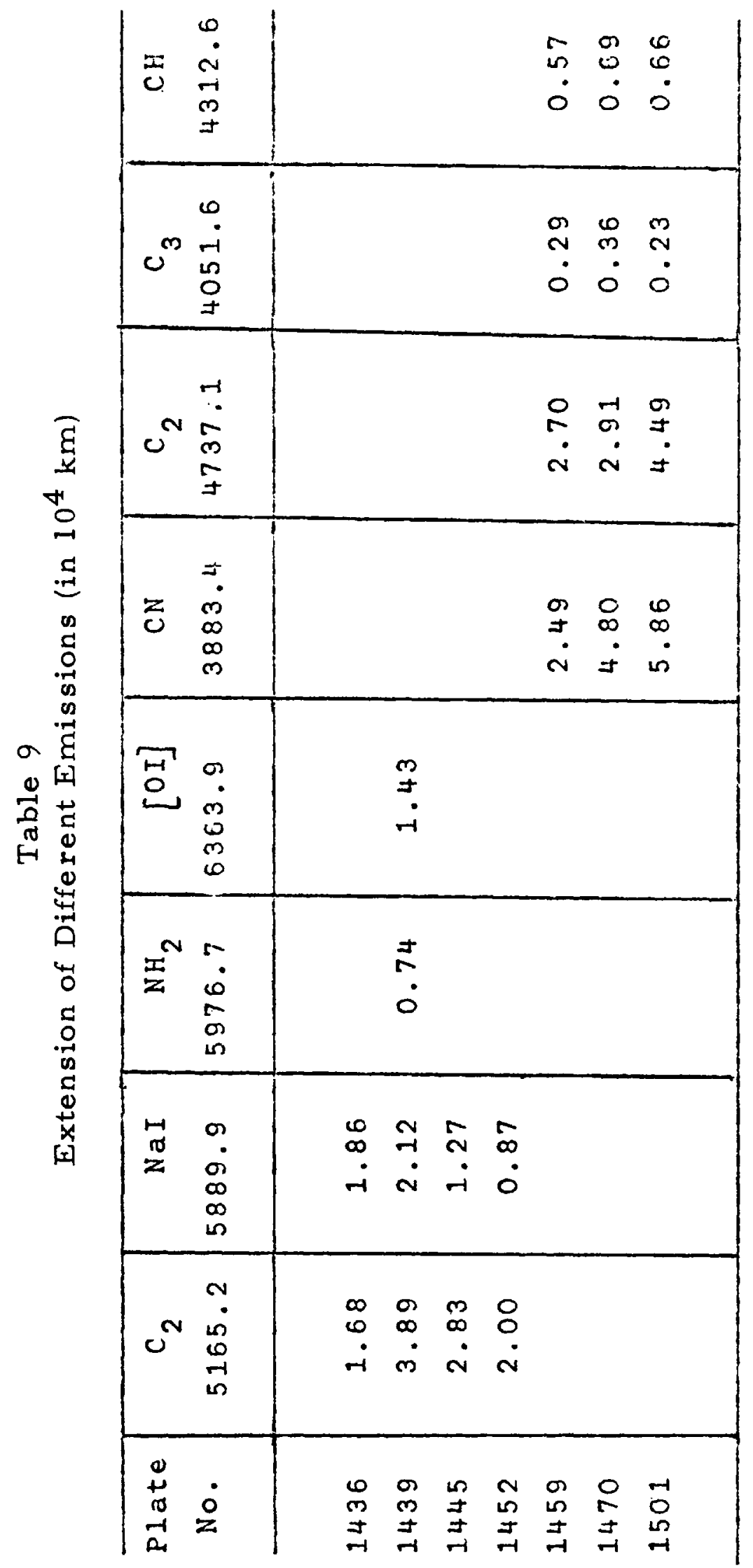


various species. Different particles show very different extensions. $C N$ has the greatest extension, $C_{3}$ the shortest. Arranged in order of decreasing extension in the head of the Comet we find $\mathrm{CN}, \mathrm{C}_{2}, \mathrm{CH}, \mathrm{C}_{3}$. Due to its faintness, the size and shape of the $\mathrm{CO}^{+}$emission could not be ietermined.

The molecular lines are superimposed on a relatively weak continuous spectrum which showed a stronger concentration toward the nucleus than the coma emissions. In comet $1973 \mathrm{f}$, the continum (relative to the discrete emissions) was weaker than that of Comets Mrkos $1957 \mathrm{~V}$ (Greenstein and Arpigny, 1962) or Bennett 1970 II (Babu and Saxena, 1972) where it was rather strong and the intensity ratio of emissions to continuum small, but it was stronger than that of the "gaseous" Comets Burnham, 1960 II (Dossin et al., 1961) or Ikeya 1963 I (Fehrenbach, 1963) where it was very weak and narrow or practically non-existent. This is in agreement with the photometric measurements (Kohoutek, 1975).

We wish to thank Mr. J. Prölss for his assistance with the reduction. We are grateful to the ESO directorate for providing us with observing time at the $1.52 \% \mathrm{~m}$ telescope and to the Stiftung Volkswagenwerk for a grant which supported this work. 


\section{References}

Babu G.S.D., Saxena P.P., 1972, Bull. Astron. Inst. czech. 23, 346

Dossin F., Fehrenbach Ch., Haser I., Swings P.,1961, Ann. d'Astrophys. 24,519

Dressler K., Ramsay D.A., 1959, Phil. Trans. R. Soc. London, A, 251, 553

Fehrenbach Ch., 1963, C.R. Paris 256, 3788

Greenstein J.L., Arpigny C., 1962, Ap. J. 135, 892

Haser L., 1957, Bull. Acad. Roy. Belg. (Classe Sci.), 5 th Series, 43,740

Hunaerts J., 1.950, Ann. l'obs. Roy. Belg., Tome $\underline{5}, 1$

Johnson R.C., 1927, Phil. Trans. R. Soc. London, A, 226, 157

Kohoutek L., 1975, this symposium

Phillips J.G., 1948, Ap. J., 108, 434

Rahe J., McCracken C.W., Donn B., 1975, Astron. Astrophys., in press

Shea J.D., 1927, Phys. Rev. 30, 825

Warner B., 1963 , Observatory 83,223

Weinard J., 1955, Ann. d'Astrophys. 18, 334

Wurm K., Balazs B., 1963, Icarus 2,334 